\title{
Building Capacity to Manage Noxious and Invasive Weeds in the Southwestern United States
}

\author{
By Anna Masayesva, Larry D. Howery, and Patricia Orr
}

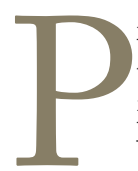
rior to the 1990s, awareness and concern regarding the negative economic and ecological impacts of invasive weeds ${ }^{i}$ on rangelands in the southwestern United States (the Southwest) was notably lacking. ${ }^{2}$ While invasive weed education and management activities were proactively being carried out in many parts of the United States during that time, only a few land management agencies in the Southwest were actively managing invasive weed populations and conducting public awareness campaigns. The need to heighten public awareness regarding invasive weeds in the Southwest was thought to be critical because the weed-infested areas in this region were considered to be relatively small and manageable compared to other regions of the United States. ${ }^{3}$

In 1994, two cooperative extension educators, one from New Mexico State University, and the other from the University of Arizona, initiated what is thought to be the first regional attempt to increase awareness of the impacts of invasive plants in the Southwest. These educators sought to increase awareness by designing and delivering the Southwestern Noxious/Invasive Weed Short Course (Short Course). The inaugural Short Course was offered in 1994 in Flagstaff, Arizona. Its primary objectives were to 1) increase awareness of invasive weed impacts (ecological and economic), 2) promote information sharing among participants, and 3) increase the capacity of land managers to manage invasive weeds. These objectives were addressed during two full days of classroom instruction and one half-day of field demonstrations. Twenty-three participants representing five federal and state agencies attended the inaugural course.

\footnotetext{
Often, the terms "noxious" or "invasive" weeds are used to apply to problematic plants, but these terms are not always considered to be synonymous. Generally, a weed is an unwanted plant that obstructs management objectives, whereas an invasive plant is one that grows and spreads rapidly, often displacing desirable native plants. ${ }^{1}$ The term "noxious" has legal ramifications for some federal agencies and states that have laws or regulations for specific plants. In this article, we use the term "invasive weeds" to describe both noxious and invasive weeds.
}

From 1995 to 2008, an expanded 3-day version of the Short Course was offered in Farmington, New Mexico. As the Short Course became more popular, it became necessary in 2002 to cap the number of participants at 100 in order to maintain the quality of instruction and the educational experience received by the participants. Also, in response to feedback from participants and demand for differing levels of education, the Short Course organizers began to offer two tracks in 2002. Track 1 was designed and delivered to first-time attendees (Beginning Track), and Track 2 was designed and delivered to participants who had previously attended the Short Course or to those who had accumulated significant experience with invasive weed issues and management over the course of their career (Advanced Track).

In April 2009, we sent a comprehensive evaluation survey to all participants who attended the Short Course from 2002 to 2008. The survey was administered to assess 1) if participants increased their awareness of the negative impacts associated with invasive weeds as a result of attending the Short Course, 2) if and how participants were applying management techniques, and 3) if and how participants were applying educational concepts learned at the Short Course. In this article, we present the results of this survey.

\section{Short Course Overview}

Each topic offered at the Short Course, although organized and taught separately by subject matter, is presented within the framework and utility of applying integrated weed management (IWM) approaches to deal with invasive plants. IWM is a process by which one selects and applies a combination of management techniques (e.g., biological, chemical, mechanical, and cultural), typically over several years, to collectively manage weed infestation (or infestations) while preserving the quality of existing habitat, water, and other natural resources. ${ }^{4}$

Short Course participants are given the option of registering for one of two course tracks based on their level of invasive weed management knowledge. Track 1 provides basic prerequisite concepts such as plant biology and ecology, 
weed identification techniques, and characteristics of invasive plants. Track 2 involves instruction on invasive weed management techniques designed to be practical and applicable to a wide variety of ecological situations and land ownership contexts. The IWM techniques and concepts learned during 2.5 days of classroom instruction are also discussed and demonstrated during a half-day field tour across northwestern New Mexico and southwestern Colorado. The field tour gives all participants the opportunity to listen to field presentations made by Short Course instructors and to ask questions about the application of various IWM practices. The field tour also allows participants to witness firsthand the negative ecological and economic impacts that invasive weed infestations can cause.

\section{Survey Development and Analysis}

We designed and administered an evaluation survey ${ }^{i i}$ following a derivation of the widely recognized total design methodology. ${ }^{5}$ Our survey consisted of 33 quantitative and qualitative questions divided into three sections: 1) Short Course format and subjects, 2) applying Short Course principles and practices, and 3) demographics of participants. We designed the survey to gather demographic information about Short Course participants, and to evaluate their perceptions on the Short Course objectives. In addition to the hard-copy mailed version of the survey, we developed an identical electronic version of the survey using the Webbased survey program, SurveyMonkey, ${ }^{\text {iii }}$ to offer participants a quick and logistically easier option for completing and returning the survey.

In April 2009, we distributed the survey to all individuals who had attended the Short Course from 2002 to 2008 (561 participants). We obtained contact information for participants from past registration lists, which included 172 mailing addresses and 389 email addresses. Using a modification of the total design method, a postcard or email reminder followed the initial survey and replacement surveys were provided upon request. Of the 172 hard-copy surveys initially mailed, 14 were returned as undeliverable. Of the 389 emails sent, 105 were returned as undeliverable. Of the 442 total successfully delivered surveys, 20 mail surveys and 110 email surveys were completed. The 130 mail and email survey responses resulted in an overall response rate of $29 \%$.

The electronic survey delivery system provided real-time qualitative (listing of open-ended responses) and quantitative summaries of survey data returned via the Web site. We added the results from surveys returned by mail to the electronic database to create a central database for all responses.

\footnotetext{
i Approval was obtained from the University of Arizona Institutional Review Board (Project 08-1045-00).

iii SurveyMonkey is available at http://www.SurveyMonkey.com.
}

We used descriptive statistics, including percentages and response counts to analyze the qualitative responses.

\section{Survey Limitations}

The relatively low response rate $(29 \%)$ to our survey could be the result of a number of factors, including the length of the survey, deviation from the total design method, and the varied survey formats. The length of the survey, 33 questions, may have been too cumbersome and time-consuming for the respondents. This is evidenced by the SurveyMonkey utility, which indicated that there were a number of surveys that were started but never completed. The implementation of our Short Course survey deviated slightly from the complete total design methodology, which consists of a four-contact sequence of prenotice letter, questionnaire, reminder postcard, and replacement questionnaire. Our modified methodology consisted of an initial mailing and only two reminders. Lastly, our preferred method for survey delivery to participants was via the SurveyMonkey Web site; however, participants that did not provide an email address were mailed a hard copy of the survey. Dillman ${ }^{6}$ asserts that hard-copy mailings are the most studied and proven method for obtaining high survey response rates.

Survey evaluations sometimes compare characteristics of participants who choose to participate vs. those who do not. This allows survey administrators to ascertain if there are significant demographic (or other) differences between respondents and nonrespondents. However, an important component of our survey design was to protect the anonymity and confidentiality of all respondents (i.e., the first page of our survey stated, "All survey responses are anonymous and completely confidential"). We considered this aspect of our survey to be an important tradeoff that likely encouraged more candid responses from the 130 respondents (29\%) who completed the survey, but that did not allow us to analyze potential differences between respondents and nonrespondents.

\section{Respondent Demographics}

The typical survey participant was a midcareer state or federal agency land manager with less than 5 years $(60 \%)$ of experience managing invasive weeds, who was responsible for managing land areas exceeding 5,000 acres (56\%) when they first took the Short Course. The respondents represented a wide variety of land managers from 19 different organizations or entities (Table 1) who were attempting to manage invasive weeds on both private and public land.

The largest percentage of respondents was between 40 and 49 years old (30\%), followed by the 30-39 (26\%), 50-59 (25\%), 20-29 (16\%), and 60-69 (4\%) age categories. Most respondents resided in either Arizona or New Mexico (88\%) but residents of California, Colorado, Nevada, Oregon, Texas, Utah, and Wyoming also responded to this survey (12\%). Of 130 respondents, 58 (44\%) had taken the Short Course more than once. 


\section{Table 1. Organizations/entities that participants were affiliated with during the year (or years) they attended the Short Course $(n=114)$}

\begin{tabular}{|l|c|}
\hline Organization & $\begin{array}{c}\text { Response } \\
\text { count }\end{array}$ \\
\hline US Bureau of Land Management & 24 \\
\hline New Mexico Department of Transportation & 19 \\
\hline Arizona Department of Transportation & 15 \\
\hline US Forest Service & 10 \\
\hline Other & 10 \\
\hline National Park Service & 8 \\
\hline US Bureau of Indian Affairs & 8 \\
\hline Soil and Water Conservation District & 8 \\
\hline Tribal government & 7 \\
\hline Cooperative extension & 5 \\
\hline Private consultant & 4 \\
\hline State lands & 4 \\
\hline New Mexico Game \& Fish Department & 3 \\
\hline US Natural Resource Conservation District & 3 \\
\hline Weed Management Area volunteer & 2 \\
\hline US Fish and Wildlife Service & 1 \\
\hline Weed Management Area paid employee & 1 \\
\hline New Mexico Department of Agriculture & 1 \\
\hline Private citizen & 1 \\
\hline
\end{tabular}

\section{Increased Awareness}

The results of our study showed that the overwhelming majority (95\%) of respondents increased their awareness and knowledge of the negative impacts (both ecological and economic) of invasive weeds as a result of attending the Short Course. As expected, first-time attendees (Track 1) showed the highest potential to learn because their baseline knowledge of invasive weed issues was generally lower than attendees who were enrolled in Track 2 (Figs. 1a and 1b). Further, our survey results indicated that over the years, participant knowledge continued to expand as evidenced by a steady increase of participants who enrolled in Track 2 (i.e., $18 \%$ in 2002 vs. $49 \%$ in 2008). After attending the Short Course, the vast majority $(>87 \%)$ of all respondents ranked their knowledge as either good or excellent in each the following areas: 1) importance of prevention and eradication of small patches of weeds, 2) general biology and ecology of weeds, and 3) how to manage or control at least one species of weed. The return of Track 1 Short Course attendees to enroll in Track 2 suggests that participants found their initial experience to be valuable and that they were eager to learn more about invasive weeds by returning to take the advanced track a year or two later.

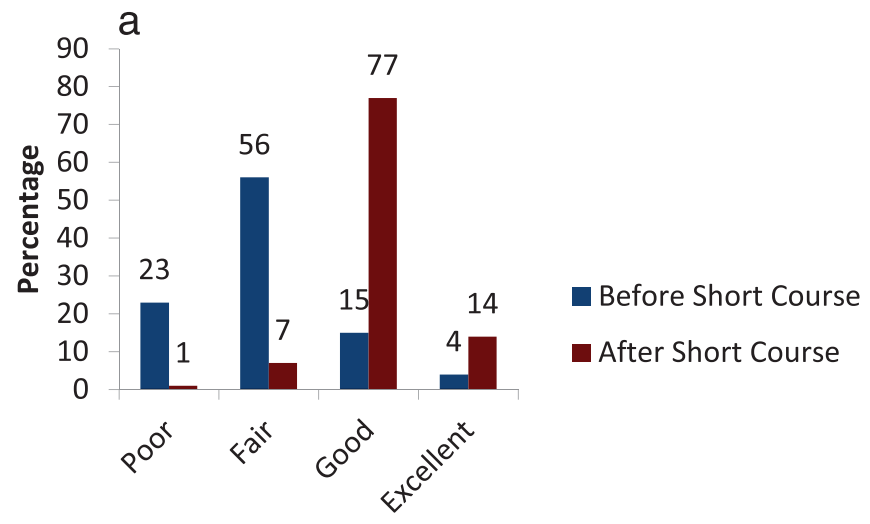

Rating

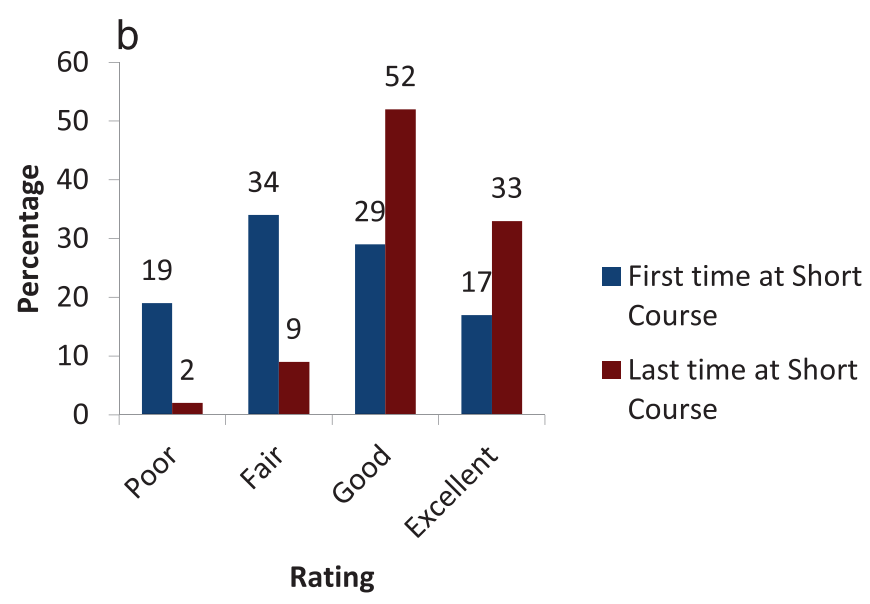

Figure 1. a-b. Percentage of one-time (a, Track 1) and repeat participants (b, Track 2) who ranked their overall knowledge of invasive weeds as poor, fair, good, or excellent before and after the Short Course. a) One-time or Track 1 participants $(n=94)$. b) Repeat or Track 2 participants $(n=58)$.

\section{Applying Invasive Weed Management Techniques}

Most respondents (77\%) indicated that the Short Course had changed the way they think about and manage invasive weeds. When asked to elaborate on how the Short Course had affected their weed management activities, the respondents indicated that the top three reasons the Short Course was "very important" to their work activities were 1) "helps me decide which treatments will be most effective" (62\%), 2) "helps me identify invasive plants" (59\%), and 3) "helps me decide when and where to apply treatments" (58\%). In contrast, respondents ranked obtaining continuing education units (37\%), grant writing (31\%), and protection against lawsuits (19\%) as "not important at all."

The survey results indicate that the Short Course's theme of couching management techniques within the context of IWM was very important. For example, both state highway departments from Arizona and New Mexico reported the importance of using IWM techniques to deal with multifaceted ecological and land ownership issues alongside highway right-of-ways that bisect public and 
private lands. The most-applied invasive weed management tool cited by respondents varied according to the primary land type that they were responsible for overseeing. For example, land managers from the US Bureau of Land Management (BLM; 37 respondents), private holdings (31), state lands (30), and tribal land (21) reported using mostly herbicides. Department of Transportation personnel used mostly mechanical control (42 respondents), whereas managers of US Forest Service lands used mostly IWM techniques (20). Conversely, managers from (or of) tribal lands (8 respondents), state land departments (12), Department of Transportation (12), private lands (14), and the BLM (15) used biological control least frequently. The US Forest Service only occasionally used mechanical control (11 respondents) or livestock (11) to control weeds.

Of all the weed management techniques presented at the Short Course, herbicide control was identified by respondents as the most commonly used tool for the management of invasive weeds. The use of herbicides for rangeland improvements has become a progressively sophisticated area of study and advancement since the 1950s. As a result, the use of herbicides in a rangeland setting requires highly trained natural resource professionals who understand the complexities of using herbicides in natural environments. ${ }^{7}$ To assist range managers in addressing these needs, the Short Course offers multiple topics on the use of herbicides, including herbicide safety, proper and legal use, registration and labeling process, evolution of herbicide industry, activity and mode of action, herbicide resistance, and effectiveness on particular species.

Biological control techniques were identified as the tool that respondents were least familiar with and had least applied. This may be due to a general lack of knowledge regarding the benefits and utility of approved biological control agents within their geographical and jurisdictional areas. The application of a successful biological control program involves the consideration of a full range of issues including the following: potential damage to nontarget plants, threatened and endangered species issues, irreversibility of a successful biological agent, expansion of an agent beyond its target area, and the impact on the potential range of the agent. ${ }^{8}$ It is possible that some respondents determined that the risks and red tape associated with this control method rendered it unfeasible within their respective land management areas. However, our survey was not designed to quantify this kind of information.

\section{Applying Invasive Weed Education Programs}

A survey conducted in California ${ }^{9}$ found that some people weren't aware of the economic and ecologic impacts of invasive weeds because they either did not know about the invasive plants in their area, or because they knew about the plants but not their impacts. Thus, the educational and information sharing component of the Short Course is very important. Most respondents (70\%) indicated that the Short Course had influenced their invasive weed educational activities.

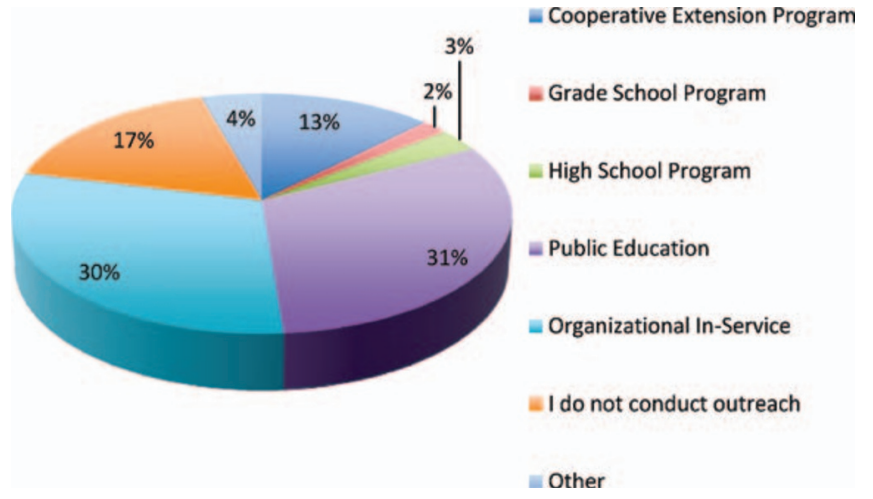

Figure 2. Percentage of participants who indicated that the Short Course helped them to conduct various types of educational programs $(n=103)$.

Respondents with educational responsibilities indicated that Short Course educational materials and information increased their capacity to develop and present invasiveweed educational programs to a variety of audiences (Fig. 2). To encourage these efforts, instructor PowerPoint presentations are mailed to participants who request them after permission is obtained from Short Course instructors. This provides a means for participants to develop and tailor their own educational programs to address their specific needs and audiences, and to continue to share Short Course information long after the 3-day event concludes.

\section{IMPLICATIONS}

Hershdorfer et al. ${ }^{10}$ recently identified 53 local weed management organizations operating in the Southwest. These organizations generally consisted of county programs, cooperative weed management areas, weed districts, and grassroots volunteer weed groups. The establishment of these organizations suggests that awareness of invasive weeds has increased significantly, and that management of invasive weeds has become a paramount concern to a broad range of

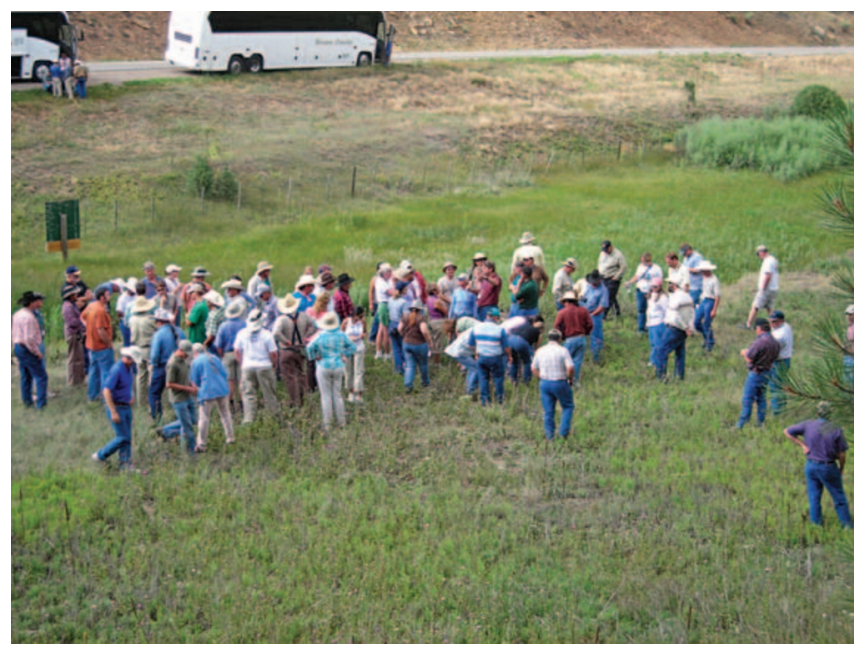

Figure 3. Short Course participants observe the implementation of biological control. Photo courtesy of Ms Cindy Lair. 


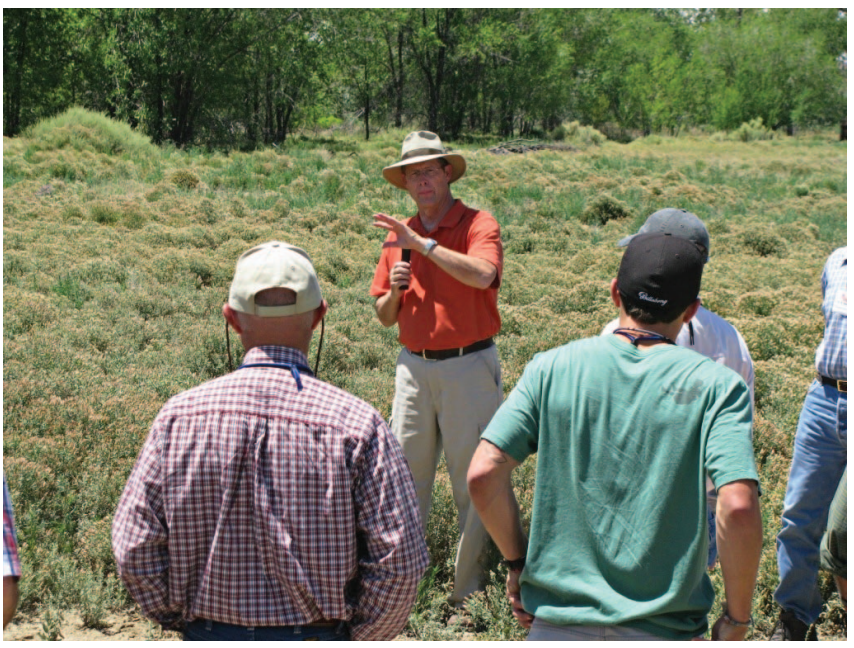

Figure 4. Dr Richard Lee conducts field-based classroom exercises. Photo courtesy of Dr Mark Ferrell.

land managers throughout the Southwest since the Short Course was first offered in 1994.

Our survey results indicate that the Short Course serves as an organized method for providing consistent weed management education to individuals who manage expansive landscapes with considerable cultural, economic, ecologic, and aesthetic value throughout the Southwest. After attending the 3-day training event, Short Course participants typically reported 1) experiencing increased awareness and knowledge of the economic and ecologic impacts of invasive weeds, 2) changing the way they thought about or applied IWM techniques/treatments, and, 3) an increased capacity to develop and conduct their own invasive weed educational programs.

Most individuals enrolling in Track 1 indicate that they do so as a starting point for learning about invasive weed management. Novice managers will continue to replace experienced managers, so Track 1 will remain a critical component of the Short Course. Some organizations (e.g., BLM) require their employees to enroll in either Track 1 or Track 2 according to their level of experience with invasive weeds and as part of their professional development program. In addition, survey data indicated that many Track 1 participants returned to take Track 2, sometimes multiple times. These findings demonstrate the need for both Tracks 1 and 2 to continue to evolve and be updated so that experienced and inexperienced weed managers alike have the most relevant information, tools, and techniques at their disposal to manage invasive weeds.

We conclude that the Short Course has helped build the capacity of land managers in the Southwest to proactively and effectively manage invasive weeds. Although the Short Course was designed to address invasive weed problems unique to the Southwest, the basic IWM principles that form the foundation of this endeavor are applicable to other geographic areas. If you would like more information on the survey described in this paper or on the Short Course, please contact the corresponding author.

\section{References}

1. USDA Forest Service. 1998. Stemming the invasive tide: Forest Service strategy for noxious non-native invasive plant management. Washington, DC, USA: USDA Forest Service. $29 \mathrm{p}$.

2. Cramer, G. C. 1995. Analysis and implementation of noxious weed policy on Bureau of Land Management and Forest Service land in Arizona [dissertation]. Tucson, AZ, USA: University of Arizona. $86 \mathrm{p}$.

3. Tidwell, L. S., and M. W. Brunson. 2008. Volunteering to manage rangeland weeds. Rangelands 30(4):19-24.

4. Carpenter, A. T., T. A. Murray, and K. Decker. 2000. Creating an integrated weed management plan: a handbook for owners and managers of lands with natural areas. Denver, CO, USA: Colorado Natural Areas Program, Colorado State Parks, and the Colorado Department of Natural Resources. 341 p.

5. Dillman, D. A. 2000. Mail and Internet surveys: the tailored design method, 2nd ed. New York, NY, USA: Wiley and Sons Inc. 544 p.

6. Dillman, D. A. 2007. Mail and Internet surveys: the tailored design method, 2007 update with new internet, visual, and mixed-mode guide, 2nd ed. Hoboken, NJ, USA: Wiley and Sons Inc. 544 p.

7. Scifres, C. J. 1977. Herbicides and the range ecosystem: residues, research, and the role of rangemen. Journal of Range Management 30:86-91.

8. McFayden Cruttwell, R. E. 1998. Biological control of weeds. Annual Review of Entomology 43:369-393.

9. Colton, T. F., And P. Alpert. 1998. Lack of public awareness of biological invasions by plants. Natural Areas Journal 18:255-265.

10. Hershdorfer, M. E., M. E. Fernandez-Gimenez, and L. D. Howery. 2007. Key attributes influence the performance of local weed management programs in the southwest United States. Rangeland Ecology E'Management 60:225-234.

Authors are Environmental Planner, Arizona Dept of Transportation, Phoenix, AZ 85007, USA, annamas@email. arizona.edu (Masayesva); Professor and Extension Specialist, School of Natural Resources and the Environment, The University of Arizona, Tucson, AZ 85721, USA (Howery); and Graduate, Department of Agricultural and Resource Economics, The University of Arizona, Tucson, AZ 85721, USA (Orr). This work was funded in part by a grant from Arizona's Renewable Resources Extension Act Program and the Alfred P. Sloan Foundation. 